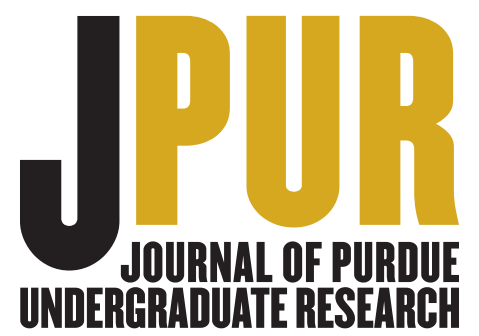

\title{
POLYTECHNIC
}

\section{A Virtual Student Federal Service (VSFS) \\ Pilot Study: Purdue University's Group \\ Project Approach to Support USAID's Efforts \\ in Global Biodiversity Conservation}

\section{Student researcher: Keita Arakawa, Freshman}

In higher education classrooms there is a lack of real-world projects/clients and limited opportunities for students to obtain internship experience. The Virtual Student Federal Services (VSFS) internship program is a government initiative that connects individual students with government agencies to complete virtual internships. A group approach to the traditionally individual VSFS internship was used to show the potential to produce meaningful outcomes to the student participants such as exposing them to virtual collaboration and developing virtual team collaboration skills.

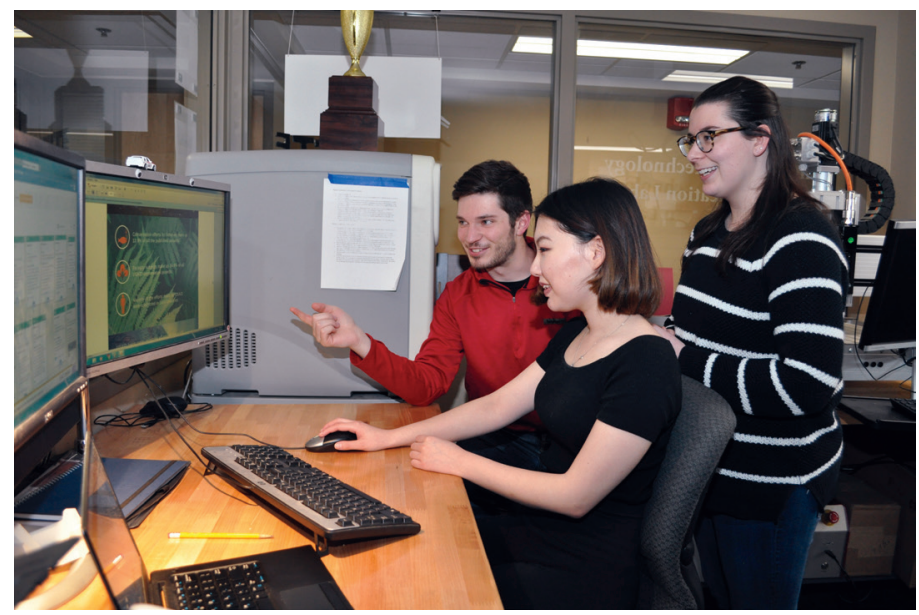

Three students working on a VSFS internship.
The study started with a literature review on research relating to virtual learning, virtual internships, and civic engagement. Then the student participants completed the VSFS internship offered in collaboration with the United States Agency for International Development (USAID). USAID requested assistance to compile various biodiversity conservation reports dating back to the 1980s from their Development Experience Clearinghouse website. The process was documented using the online design and collaboration platform, Sprintbase. Sprintbase uses digital bulletin boards that users in a group can use to post and vote. This tool guided the participants to share insights from their research. The student participants helped the U.S. government create a data management system that facilitates evidence gathering, research, and diffusion of knowledge in support of global biodiversity conservation. Students benefitted by refining skills such as communication, conflict resolution, problem-solving, and organizational skills. Unfortunately, due to the government shutdown, time was limited. This potentially impacted the results of this pilot study. In the future, there is hope to possibly take VSFS internships out of extracurriculars and into the postsecondary classroom setting.

Research advisor Lisa Bosman writes: "Keita's research with the government-sponsored VSFS program has the potential to disrupt how we offer design projects in STEM classrooms. As we move towards the desire to integrate humanities into STEM and offer more opportunities for transdisciplinary thinking, digital civics and the VSFS program might be just what higher education is looking for." 